\title{
Silicone Y-Stent Placement on the Secondary Left Carina
}

\author{
Masahide Oki Hideo Saka \\ Department of Respiratory Medicine, Nagoya Medical Center, Nagoya, Japan
}

\author{
Key Words \\ Airway stenosis · Airway stent · Bronchoscopy · Central \\ airway obstruction $\cdot$ Stent
}

\begin{abstract}
Background: The silicone Y-stent has mainly been used for the treatment of lesions around the main carina, and only a few case reports have been published on the technique for the lesions around the secondary left carina (LC2). Objectives: We investigated the feasibility, efficacy and safety of a stenting technique using a silicone Y-stent for patients with airway stenosis around LC2. Methods: Patients who underwent airway stent placement between December 2010 and September 2014 in a single center were retrospectively reviewed. Under general anesthesia, using rigid and flexible bronchoscopes, the airway lumen was re-established followed by Y-stent placement on LC2. Results: We performed 274 airway stenting procedures for 253 patients during the study period. Twelve of them ( 7 with lung cancer, 3 with esophageal cancer/carcinosarcoma, 1 with thyroid cancer and 1 with renal cancer) underwent a Y-stent placement on LC2. Respiratory symptoms were relieved in all patients. Six of 7 patients with supplemental oxygen, including the mechanically ventilated patient before stent placement, could be discharged without supplemental oxygen. The chest radiograph after the procedure showed increased lung volume in all 7 patients with partial or complete atelectasis. Median survival after stenting was 197 days at the
\end{abstract}

time of data collection. Retention of secretions occurred in 1 and hemoptysis in another patient. Conclusions: Silicone Y-stent placement on LC2 is technically feasible, effective and acceptably safe.

(c) 2015 S. Karger AG, Basel

\section{Introduction}

Airway stent placement has been known as a useful palliation in patients suffering from airway stenosis [14]. The stents should be inserted so as to cover the whole stenotic region, with a shape selected to fit the anatomical structure of the airway. Formerly, there was no ideal stenting for covering the peripheral bifurcation beyond the main carina. However, recent modification of stenting techniques has enabled stenting on the main carina and the carina between the bronchus to the right upper lobe and the bronchus intermedius (primary right carina, RC1 [5]) using a silicone Y-stent [6-10], and a dedicated bifurcated silicone stent [11] is now available for maintaining airway patency of the right main stem bronchus, bronchus intermedius and the right upper lobe bronchus.

Similarly, we sometimes encounter patients with airway stenosis or fistula around the carina between the bronchus to the lingular segment of the left upper lobe

Preliminary data were previously presented at the ATS 2015 Annual Meeting in Denver, Colo., USA.

\section{KARGER 125}

C 2015 S. Karger AG, Basel

0025-7931/15/0906-0493\$39.50/0 
Fig. 1. Patient flowchart.

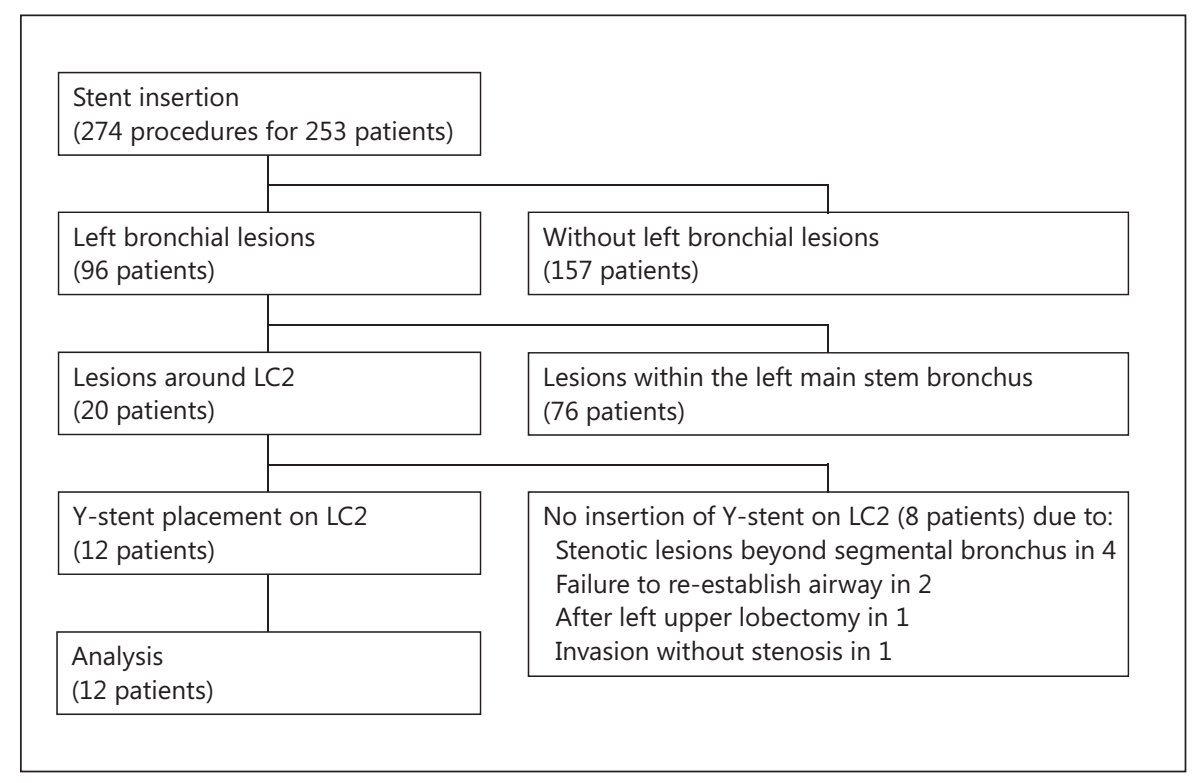

and the left lower lobe bronchus (secondary left carina, LC2 [5]). For such patients, the Y-stenting technique may be applicable. However, only a few case reports [12] have been published on the technique for the LC2 lesions. In this retrospective study, we investigated the feasibility, efficacy and safety of the Y-stent placement on LC2.

\section{Patients and Methods}

\section{Patients}

From December 2010 to September 2014, we performed 274 airway stenting procedures for 253 patients with airway stenosis, obstruction or fistula at the Nagoya Medical Center. Among the patients, 12 underwent Y-stent placement using a Dumon Y-stent (Novatech, La Ciotat, France) on LC2. The medical records of these 12 patients were retrospectively reviewed. The main indication of this technique was cases with airway stenoses, fistula or bleeding around LC2, in whom the endobronchial wall can be covered with a Y-stent but not a straight stent. We did not consider that there was an indication for patients, in whom the bronchus beyond the segmental bronchus was invaded and obstructed (e.g. patients with a tumor extended from the peripheral bronchus). Prior to stent placement, written informed consent for the procedure was obtained from all patients and/or their families. This study was approved by the institutional review board of the $\mathrm{Na}$ goya Medical Center (identifier: 2014-801).

\section{Procedures}

Stenting procedures were performed by both rigid and flexible bronchoscopes under general anesthesia. First, the airway lumen was re-established with argon plasma coagulation, electrocautery, cryotherapy, high-pressure balloon and the bevel of the rigid bronchoscope. Then, a Y-stent was implanted on LC2 as follows. The length and size were measured using a flexible bronchoscope, balloon-type radial probe endobronchial ultrasound and preprocedural chest computed tomography, as previously described [6]. Then the limbs of the Y-stent were cut to appropriate lengths. After that, the stent was loaded into the stent introducer. After the rigid bronchoscope was advanced as far as possible into the left main bronchus, the stent introducer loaded with a stent was advanced into the rigid bronchoscope and pushed out into the left main stem bronchus with a stent pusher. Finally, the stent was grasped with a rigid forceps and pushed so as to straddle the LC2 by rotating or moving it forward and backward with or without fluoroscopic guidance. According to our routine clinical practice, antibiotics were given after the procedure. Acetylcysteine nebulization was performed 3 or 4 times daily to prevent mucus retention.

\section{Results}

\section{Patients}

We performed 274 airway stenting procedures for 253 patients during the study period. Twelve of them (median age 69 years, range $34-72$; all male) who underwent a Ystent placement on LC2 were analyzed. The patient flowchart is shown in figure 1 . All patients had malignant diseases. Median survival after stenting was 197 days (range $32-1,266)$ at the time of data collection.

\section{Procedures}

The procedural details are shown in table 1 . All patients underwent Y-stent placement on LC2 using the smallest Dumon Y-stent with $14 \times 10 \times 10 \mathrm{~mm}$ in outer 
Table 1. Procedural details of 12 patients who underwent Y-stenting on the LC2

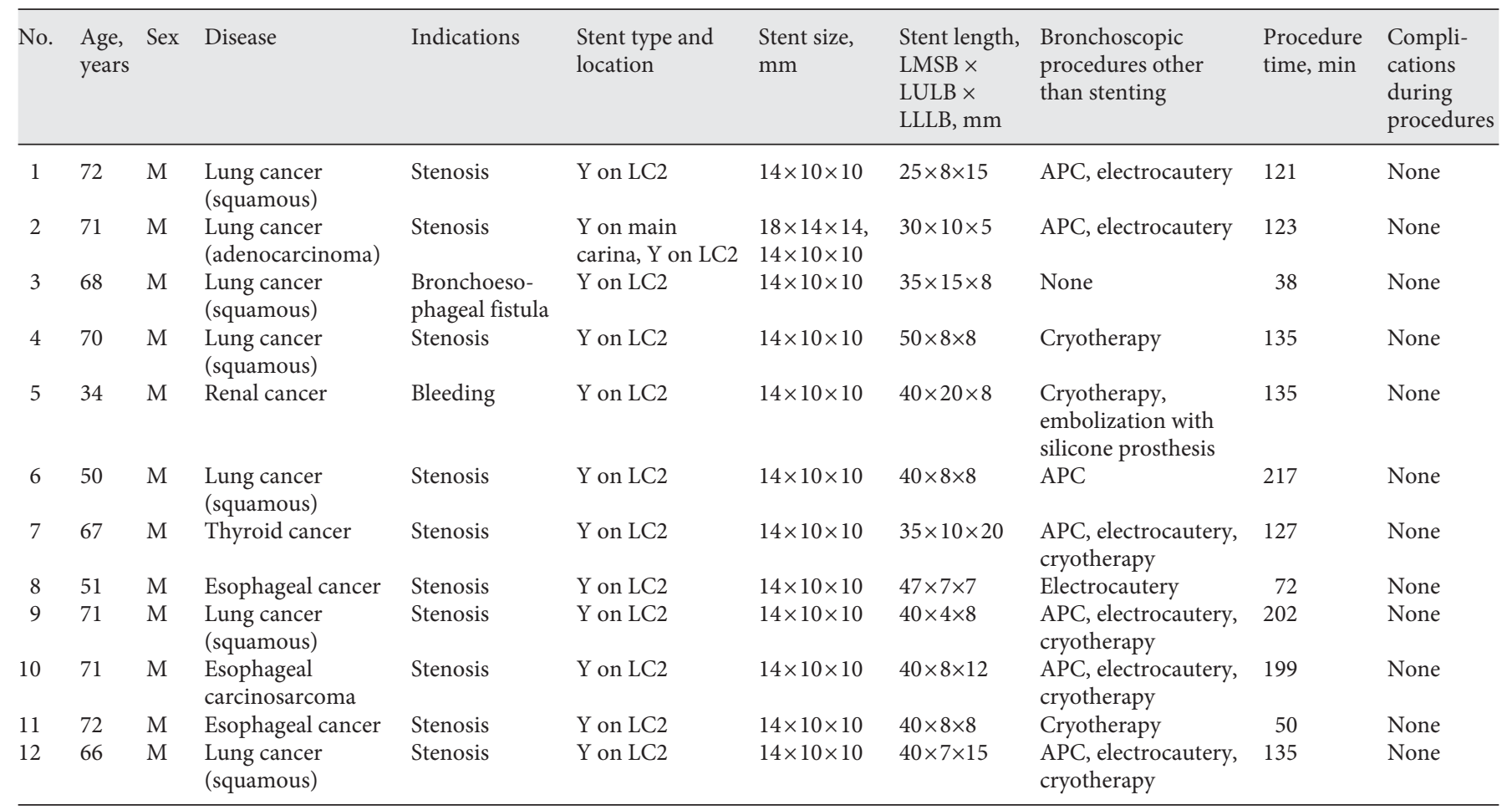

LMSB = Left main stem bronchus; LULB = left upper lobe bronchus; LLLB = left lower lobe bronchus; APC = argon plasma coagulation.

Table 2. Results in 12 patients who underwent Y-stenting on the LC2

\begin{tabular}{|c|c|c|c|c|c|c|c|c|c|}
\hline No. & $\begin{array}{l}\text { Age, } \\
\text { years }\end{array}$ & Sex & Disease & $\begin{array}{l}\text { Supplemental } \\
\mathrm{O}_{2} \text { before/after } \\
\text { stenting, } 1 / \mathrm{min}\end{array}$ & $\begin{array}{l}\text { Improvement } \\
\text { of respiratory } \\
\text { symptoms }\end{array}$ & $\begin{array}{l}\text { Improvement } \\
\text { of atelectasis } \\
\text { on X-ray }\end{array}$ & Complications & $\begin{array}{l}\text { Survival, } \\
\text { days }\end{array}$ & Others \\
\hline 2 & 71 & M & Lung cancer (adenocarcinoma) & $0 / 0$ & - & No atelectasis & None & 32 & \\
\hline 3 & 68 & M & Lung cancer (squamous) & $0 / 0$ & - & No atelectasis & None & 321 & $\begin{array}{l}\text { Esophageal } \\
\text { stenting after } \\
\text { procedures }\end{array}$ \\
\hline 6 & 50 & M & Lung cancer (squamous) & $0 / 0$ & - & - & None & $1,266^{\mathrm{a}}$ & $\begin{array}{l}\text { Left pneu- } \\
\text { monectomy } \\
\text { after } \\
\text { procedures }\end{array}$ \\
\hline 11 & 72 & $\mathrm{M}$ & Esophageal cancer & $5 / 0$ & - & - & None & 48 & \\
\hline 12 & 66 & $\mathrm{M}$ & Lung cancer (squamous) & $6 / 0$ & - & - & None & $214^{\mathrm{a}}$ & \\
\hline
\end{tabular}

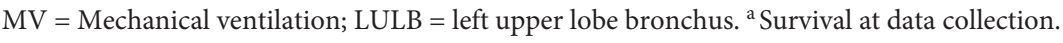


Fig. 2. a Bronchoscopic view before stent placement showing the left main stem bronchus invaded by lung cancer (squamous cell carcinoma). b Bronchoscopic view of LC2 after re-establishment of airway lumen. c Bronchoscopic view of LC2 after stent placement. d Distal end of Ystent in the bronchus to the lingular segment of the left upper lobe. e Chest roentgenogram after Y-stent (arrowheads) placement. $\mathrm{LMB}=$ Left main stem bronchus; LLLB = left lower lobe bronchus; LULB = left upper lobe bronchus.

Fig. 3. a Bronchoscopic view before stent placement showing bronchoesophageal fistula located at the entrance of the left lower lobe bronchus. b Bronchoscopic view of LC2 after stent placement. c Distal end of Y-stent in the bronchus to the lingular segment of the left upper lobe. d Distal end of Y-stent in the left lower lobe bronchus. e Chest roentgenogram after Y-stent (arrowheads) placement. LLLB $=$ Left lower lobe bronchus; LULB = left upper lobe bronchus; $\mathrm{BB}=$ basal bronchus; $\mathrm{SB}=$ superior bronchus.
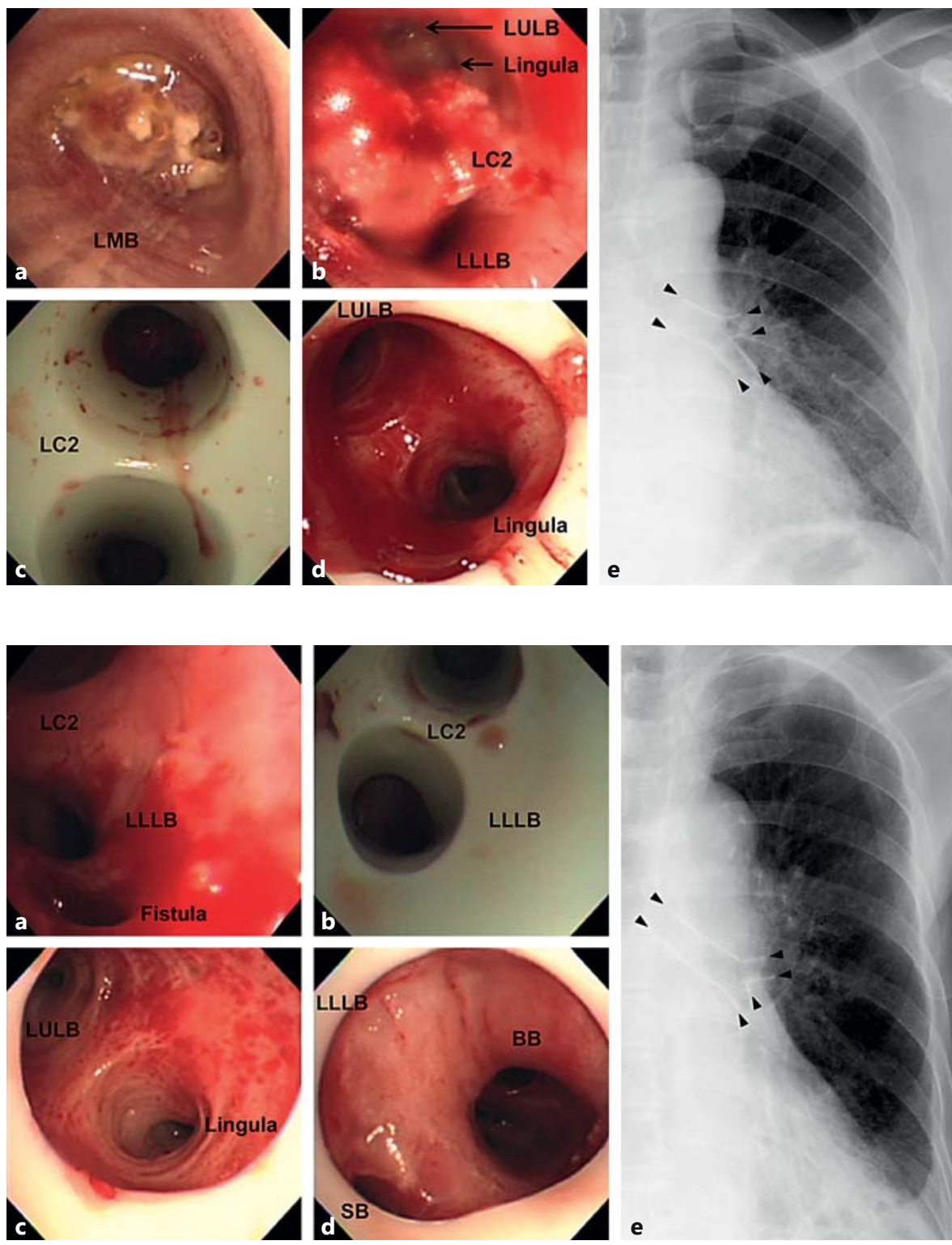

diameter. The median lengths of limbs of the left main stem bronchus, the bronchus to the lingular segment of the left upper lobe and the left lower lobe bronchus were 40,8 and $8 \mathrm{~mm}$, respectively. Eleven of the 12 patients were newly stent-implanted patients, and the remaining one was included for stent replacement due to progression of lung cancer beyond the left bronchial limb of the main carinal Y-stent. The median procedure time was 131 min (range 38-217).

\section{Efficacy}

The results after stent placement are shown in table 2 . Respiratory symptoms were relieved in all patients
(100\%), based on their medical and stenting records. Six of 7 patients (86\%) with supplemental oxygen, including the mechanically ventilated patient before stent placement, could be discharged without supplemental oxygen. The chest radiograph after the procedure showed increased lung volume in all 7 patients (100\%) with partial or complete atelectasis.

\section{Safety}

Retention of secretions which required bronchoscopic mucus removal occurred in 1 and hemoptysis which might be associated with the stenting was found in another patient. 


\section{Representative Cases}

A 72-year-old man with lung cancer (squamous cell carcinoma, T2aN3M0) complained of dyspnea (case 1 in tables 1 and 2). Chest CT revealed that the left main stem bronchus was occluded by a tumor. The patient underwent rigid bronchoscopic treatment under general anesthesia. The occluded left main stem bronchus (fig. 2a) was re-established using argon plasma coagulation and electrocautery. LC2 was invaded by a tumor (fig. 2b), and so a Y-stent was placed to cover the LC2 (fig. 2c-e). Respiratory symptoms and pulmonary function (VC: from 1.81 to 2.48 liters; $\mathrm{FEV}_{1}$ : from 1.26 to 1.80 liters; peak expiratory flow: from 3.23 to 5.41 liters/s) improved immediately after the procedure. The patients received chemotherapy and radiation therapy after the procedure.

A 68-year-old man with lung cancer (squamous cell carcinoma, T2aN2M0) who received chemotherapy and radiation therapy suffered from pneumonia due to a bronchoesophageal fistula (case No. 3 in tables 1 and 2). The fistula was located just at the entrance of the left lower lobe (fig. 3a), which seemed too peripheral to be covered by a silicone or metallic straight stent. The patient underwent Y-stent placement on LC2, which successfully sealed the fistula (fig. $3 \mathrm{~b}-\mathrm{e}$ ). After the procedure, an additional esophageal stent was implanted. The procedures permitted oral ingestion.

\section{Discussion}

To our knowledge, this is the first study on the usefulness of silicone Y-stenting for lesions around LC2. Our study demonstrated that this technique is feasible for most cases with indications and provides immediate relief of the symptoms and the amount of supplemental oxygen without major complications.

Various materials and shapes of airway stents have been developed so far and are now available [1-3]. Above all, the silicone stent is still one of the gold standards because of its easy removability, customizability, durability and low cost [1-3]. Although Dumon Y-stents were originally invented and have been commonly used for the treatment of the main carinal stenosis $[13,14]$, recent studies [6-10] have suggested that they can be used for the stenosis around $\mathrm{RC} 1$. However, the main carinal angle differs from the primary right carinal angle, so when we insert a Y-stent on $\mathrm{RC} 1$, the proximal and distal orifice of the limbs of the Ystents must be cut obliquely so that each orifice faces the bronchial lumen but not the bronchial wall [6]. To overcome this limitation, a dedicated bifurcated silicone stent designed to fit on the RC1 was developed, and its clinical efficacy has been reported $[11,15,16]$. The number of patients with indications for placing bifurcated stents on RC1 is higher than that for stents on LC2 in our clinical practice. In fact, we performed stenting with the bifurcated silicone stent (Dumon Y or OKI, Novatech) on RC1 in 44 patients during the study period. However, as we demonstrated in the current study, the Y-stenting technique on LC2 is clearly beneficial in certain cases.

The angle of LC2 is similar to that of the main carina [17], so the Y-stents fit LC2 better than RC1. Therefore, the technique of Y-stenting for LC2 seems to be easier than that for RC1. The right upper lobe bronchus branches off at an acute angle, so the insertion technique of the Y-stent limb into the right upper lobe bronchus is often complicated [6, $8,9]$. A limitation of the Y-stent for placing it on LC2 may be its large diameter. In the standard lineup of Dumon Ystents, the smallest one has limbs of $14 \times 10 \times 10 \mathrm{~mm}$ in outer diameter. As shown in figure $1, \mathrm{Y}$-stent placement on LC2 was feasible in most cases with indications; however, our cases were all male, and the smallest Y-stents were used in all cases. Despite the high feasibility in the current study, we hope the addition of smaller Y-stents to the Dumon Ystent lineup will meet the needs of various-sized bronchi.

The Y-stenting technique for the left bronchus differs somewhat from that for the right bronchus due to the difference in anatomical structure. First, the distance from LC2 to the next bronchial branch (the superior segment of the left lower lobe bronchus) is short because the left bronchus has no corresponding part of the bronchus intermedius in the right bronchus. In addition, the length of the peripheral limbs of the Y-stent required in the current study was similar (both median $8 \mathrm{~mm}$ ). Therefore, only the pushing method but not the pulling back method [14] can be used for deploying the Y-stent. Second, the left main stem bronchus branches off at an acute angle from the trachea and is longer than the right main stem bronchus. Thus, rigid bronchoscopes, or even rigid forceps in some cases, do not reach the LC2, and so the Y-stent should be inserted while grasping its proximal limb with a rigid forceps. To facilitate the grasping and/or manipulation of the stent with the rigid forceps, the proximal limb of the Y-stent should be cut long. In fact, the median length in our cases was as long as $40 \mathrm{~mm}$. Third, the bronchus of the left lower lobe branches just beyond LC2, so the tumor invades the superior bronchus as well as LC2 in some cases. In such cases, one must sacrifice the bronchus while covering the bronchial orifice. In cases with airway patency of the superior bronchus of the left lower lobe, the stent limb can be cut somewhat obliquely so as not to cover the bronchial orifice. 
The present Y-stenting technique is likely to allow stent insertion into the most distal bronchus. Therefore, if the tumor extends beyond the peripheral limb and occludes the bronchi, there is no indication for bronchoscopic recanalization or stent replacement. In fact, the peripheral bronchi were finally invaded and occluded by a tumor in some cases. Although the duration of stent implantation effectiveness by maintaining the peripheral bronchial patency may be shorter than the central bronchial patency, the use of the present technique to improve respiratory symptoms immediately and decrease supplemental oxygen seems to be justified. In addition, it is well known that an implanted Ystent has excellent stability $[13,14]$, which is seldom associated with migration. Even in cases in whom the peripheral part of the left main stem bronchus but not LC2 is invaded, the Y-stenting technique on LC2 may be an alternative to the conventional straight cylinder-type stent placement in terms of its anti-migration characteristic.

Nowadays, covered self-expanding metallic Y-stents are available on the market [18]. Although they were designed to fit on the main carina, some manufacturers produce individualized ones upon request, so customized small metallic $\mathrm{Y}$-stents may also be used for lesions around LC2. The pushing method of silicone stents bears the risk of traumatizing the bronchial membrane because the stents must be pushed forward blindly. The metallic Ystents, on the other hand, can be inserted with the help of guidewires, so it may be less traumatizing in some cases, especially in cases with a fistula. In addition, it may minimize the procedures for recanalizing airways, which is indispensable during silicone stenting. Although we have no direct experience, metallic Y-stenting may well be an alternative to silicone Y-stenting for lesions around LC2.

The limitation of this study is its small retrospective nature. A larger prospective study is necessary to elucidate the details of this procedure. In addition, our institution has extensive experience in silicone Y-stent placement. The good results of our study might not be reproduced by less experienced hands. However, the Y-stenting technique for LC2 seems to be easier than that for RC1, so if the bronchial lumen is re-established enough and a Y-stent with an appropriate size and length is selected, the insertion does not seem to be difficult.

In conclusion, the silicone Y-stent placement on LC2 for patients with lesions around this area is technically feasible, effective and acceptably safe.

\section{Financial Disclosure and Conflicts of Interest}

The authors have no conflicts of interest to disclose.

\section{References}

1 Freitag L: Airway stents. Eur Respir Mon 2010;48:190-217.

-2 Gompelmann D, Eberhardt R, Herth FJ: Advanced malignant lung disease: what the specialist can offer. Respiration 2011;82:111123.

- 3 Bolliger CT, Sutedja TG, Strausz J, Freitag L: Therapeutic bronchoscopy with immediate effect: laser, electrocautery, argon plasma coagulation and stents. Eur Respir J 2006;27: 1258-1271.

4 Mahmood K, Wahidi MM, Thomas S, Argento AC, Ninan NA, Smathers EC, Shofer SL: Therapeutic bronchoscopy improves spirometry, quality of life, and survival in central airway obstruction. Respiration 2015;89:404413.

5 Prakash UBS, Fontana RS: Functional classification of bronchial carinae. Chest 1984;86: 770-772.

6 Oki M, Saka H, Kitagawa C, Kogure Y: Silicone y-stent placement on the carina between bronchus to the right upper lobe and bronchus intermedius. Ann Thorac Surg 2009;87: 971-974.
7 Shioi R, Yasuo M, Ushiki A, Tanabe T, Tsushima K, Hanaoka M, Kubo K, Moteki H, Takumi Y, Kawakami S, Kurozumi M, Hirose Y: Management of right upper airway patency by a silicon stent in a case of endobronchial metastasis. Respir Med CME 2009;2:191-196.

-8 Oki M, Saka H, Kitagawa C, Kogure Y, Mori K, Kajikawa S, Adachi T: Double Y-stent placement for tracheobronchial stenosis. Respiration 2010;79:245-249.

-9 Oki M, Saka H: Double Y-stenting for tracheobronchial stenosis. Eur Respir J 2012;40: 1483-1488.

10 Lee HJ, Puchalski J, Sterman DH, Bhadra K, Kumar R, Gillespie CT, Haas AR: Secondary carina $Y$-stent placement for post-lung-transplant bronchial stenosis. J Bronchol Inter Pulmonol 2012;19:109-114

11 Oki M, Saka H: New dedicated bifurcated silicone stent placement for stenosis around the primary right carina. Chest 2013;144:450-455.

12 Murgu SD, Colt HG: Silicone Y stent placement at secondary left carina for malignant central airway obstruction. J Thorac Cardiovasc Surg 2010;139:494-495.

13 Dumon JF, Dumon MC: Dumon-Novatech Y-stents: a four-year experience with 50 tracheobronchial tumors involving the carina. J Bronchol 2000;7:26-32.
14 Dutau H, Toutblanc B, Lamb C, Seijo L: Use of the Dumon Y-stent in the management of malignant disease involving the carina: a retrospective review of 86 patients. Chest 2004; 126:951-958.

15 Dahlqvist C, Ocak S, d'Odémont JP: New bifurcated silicone stent for the treatment of posttransplant bronchus intermedius stenosis: new silicone stent in posttransplant stenosis. Chest 2014;145:429.

-16 López-Padilla D, García-Luján R, de Pablo A, de Miguel Poch E: Oki stenting for anastomotic bronchomalacia in lung transplantation. Eur J Cardiothorac Surg 2015;48:e53e54.

17 Deshmukh V, Zuccatosta L, Sediari M, Mei F, Gasparini S, Salvolini L: Stenting right main bronchus with montgomery $\mathrm{T}$ tube for upper lobe ventilation. J Bronchology Interv Pulmonol 2010;7:90-92.

18 Gompelmann D, Eberhardt R, Schuhmann M, Heussel CP, Herth FJ: Self-expanding Y stents in the treatment of central airway stenosis: a retrospective analysis. Ther Adv Respir Dis 2013;7:255-263. 